\title{
KNOWLEDGE OF SLUM COMMUNITY TOWARD LEPROSY: A CROSS-SECTIONAL SURVEY FROM KARAD URBAN BLOCK OF WESTERN MAHARASHTRA, INDIA
}

\author{
RAJSINH VISHWASRAO MOHITE* \\ Department of Community Medicine, Krishna Institute of Medical Sciences, Karad - 415 110, Maharashtra, India. Email: \\ rajsinhmohite124@gmail.com
}

Received: 23 October 2017, Revised and Accepted: 12 December 2017

\begin{abstract}
Objectives: The objectives of this study are to assess the knowledge of urban slum community toward leprosy and to determine the relationship between sociodemographic variables and knowledge about leprosy.

Methods: The study was planned during September 2016 to October 2016, as a community-based cross-sectional survey conducted at Karad urban slum area of state Maharashtra, India. The sample size calculated was a total of 246 slum community members, aged 20-60 years, enrolled randomly and interviewed by utilizing pre-tested structured pro forma. Data collected were analyzed and presented in tabular form. Chi-square test was used to determine the association between study variables.
\end{abstract}

Results: A total of 246 respondents were interviewed of which maximum $42.2 \%$ were in the age group $30-40$ years. The problem of illiteracy was $25.6 \%$ and maximum $67.4 \%$ were engaged in daily wage labor force. The overall knowledge about leprosy was poor responded by more than half (55.6\%) of the study participants. Maximum, 78\% slum dwellers knew about leprosy disease, whereas their knowledge about the cause of disease, sign, and symptoms, infectivity and curability was around $50 \%$. Maximum $68 \%$ of participants responded that disease is confined to poor people. The age, education, and occupational status of slum dwellers were significantly associated with knowledge about leprosy.

Conclusion: The present study concluded that poor knowledge of slum community toward leprosy could be an important determinant of poor performance of the National Leprosy Eradication Programme at urban community.

Keywords: Leprosy, Knowledge, Association, Slum community.

(C) 2018 The Authors. Published by Innovare Academic Sciences Pvt Ltd. This is an open access article under the CC BY license (http://creativecommons. org/licenses/by/4. 0/) DOI: http://dx.doi.org/10.22159/ajpcr.2018.v11i3.22494

\section{INTRODUCTION}

Leprosy, one of the chronic and oldest infectious diseases, rilled with so many myths and carries grave social stigma and ostracism which compels the patients to hide disease resulting in the manifestation of deformities which results in multidimensional problems not only to patient and family but also to community and nation [1-3]. Considering leprosy as a major public health problem, the Government of India launched the National Leprosy Elimination Programme which tremendously reduced the problem statement and India, achieved leprosy elimination by the end of the year 2005 [4]. The knowledge of community members toward leprosy is of paramount in the management of disease, drug therapy, communication, and counseling skill. Follow-up, problem-solving skills, the motivation of patient, family members, and community are essential for reducing the burden of disease as well as to prevent the reemergence of disease in the community.

Leprosy elimination was achieved by Satara district of state Maharashtra by the end of the year 2005, but still, disease has had a high burden in an urban area as compared to the rural area could be due to hidden cases reported from slum habitations [5]. Neglected slum population, migration problem, lack of adequate health care facilities and health workforce, and increased drug resistance may lead to the high burden of diseases in urban area [6,7]. To address, leprosy as a major public health problem; needs intensified use of information education and communication as well as slum leprosy elimination activities for further reducing the disease burden and stigma towards leprosy in urban slum area. The rising prevalence of leprosy is often associated with lack of accurate knowledge about leprosy in the community could be an important factor in hindering leprosy control [8].
The study was done with the objectives to assess the knowledge status of Karad urban slum community toward leprosy disease and to find the association between sociodemographic characteristics of slum dwellers with their knowledge status. Karad is a small town located at the confluence of river Krishna and Koyana and has strong political, educational, social, and economic background. Since the past two decades, migration is a big threat which leads to increased urban slum areas which adversely affect the problem statement of leprosy in the form of reemerging disease. Our intension is to address the behavior of slum community toward leprosy, and according to the findings, formulates program and policies to combat leprosy as a public health threat.

\section{METHODS}

A community based, cross-sectional study was carried out in Karad urban slum area under the field practice area of the Department of Community Medicine, Krishna Institute of Medical Sciences Karad, state of Western Maharashtra, India. The house-to-house survey was conducted in the year 2016 over 3 months. At the time of the survey, a total of 255 households (Zopadi) were present in the study area, and population under study includes whole community with age ranges from 18 to 60 years. The sample size included 246 households as a head of family or next person enrolled by random selection from family. Nine households were excluded from the study due to temporary outmigration and not willing to participate in the survey. Structured pro forma was used to collect data with respect to assessing the knowledge of study attendees and was tested for its validity and reliability from experts in leprosy followed by a pilot study to correct ambugations included for knowledge specific questions. Informed written consent 
was obtained from each study participant in vernacular language, and maximum attempts were made to maintain privacy and confidentiality at the time of interview. Ethical approval for the study was obtained from the Institute Ethical Committee.

Data so were collected from respondents by personal interview method at household level with the help of Medical Social Workers. Data were entered in Microsoft Excel 2007, coding and decoding were performed and analyzed for knowledge as, who responded correctly were given scored " 1 " and with no or do not know, scored as "0" and total score was obtained. The data were presented in tabular form with frequency percentage distribution, and Chi-square test was applied to determine the association between sociodemographic variables with knowledge of slum dwellers toward leprosy using statistical software In-Stat.

\section{RESULTS}

In the present study, the baseline data comprised a total of 246 slum community members were interviewed have had low and high of age ranged from 18 to 57 years, respectively, of which maximum $42.27 \%$ belonged to age group 30-40 years. The higher proportion of participants $54.47 \%$ was males, $46.74 \%$ enrolled for primary education; however, $25.60 \%$ were illiterate and maximum $63.41 \%$ were doing the job of daily wage laborers (Table 1 ).

Of the 246 study participants who responded, 192 (78\%) identified as having knowledge about leprosy disease. Similarly, $78.5 \%$ also reported that leprosy has been transmitted by close contact. Maximum, 58.3\% of participants were responded the sign and symptoms of leprosy. Surprisingly, more than half of participants, $56.7 \%$, believed that disease is curable and $52.9 \%$ responded availability of highly effective anti-leprosy treatment at Primary Health Centre/Community Health Centre as public health institutions but only $46 \%$ knew that treatment is of free of cost. It was shocking that $18.6 \%$ knew about the National Leprosy Eradication Programme launched by the Government of India to tackle leprosy at the national level. Whereas, some members, $51.6 \%$ responded as health education is an important tool to improve the knowledge of community toward leprosy program (Table 2).

According to knowledge category, community members were categorized as poor knowledge category $(0-4)$, fair knowledge category (5-8), and good knowledge category (9-13)

Maximum, 55.6\% of participants had a poor quality of knowledge about leprosy, whereas $31.7 \%$ and $12.6 \%$ had fair and good knowledge, respectively. The knowledge score ranges from minimum 2 to maximum 12 with mean $4.69 \pm 2.08$ (Table 3).

The sociodemographic factors which were identified to be having statistically significant ( $\mathrm{p}<0.05$ at $95 \%$ confidence interval) association with poor knowledge of slum attendees interviewed in present study toward leprosy disease were age in years $\left(\chi^{2}=24.69 ; \mathrm{p}=0.0004^{* *}\right)$, illiteracy and low level of education $\left(\chi^{2}=69.53 ; p=0.0001^{* *}\right)$, and occupation like daily wage laborers $\left(\chi^{2}=34.21 ; p=0.0001^{* *}\right)$. However, gender could not show any influences on the status of knowledge about leprosy among slum dwellers $\left(\chi^{2}=1.53 ; \mathrm{p}=0.46\right)$ (Table 4$)$.

\section{DISCUSSION}

The World Health Organization recommended integration of leprosy services into general health services to combat leprosy as a public health threat. It also further stated to render quality antileprosy services to the doorstep of the community to improve knowledge and perception among general population toward leprosy. The present study revealed that 137 (55.6\%) slum community respondents had overall a poor knowledge about leprosy, whereas very few (12.6\%) had overall a good knowledge. A community-based study conducted by John AS in Kolkata [9] slum area has been also reported poor knowledge of community participants toward leprosy. Somewhat similar findings also reported by Danturty I from Secunderabad [10], an urban slum community of state Telangana.
Table 1: Baseline characteristics of slum community members $(n=246)$

\begin{tabular}{ll}
\hline Sociodemographic characteristic & Frequency (\%) \\
\hline Age (years) & \\
$18-30$ & $45(18.29)$ \\
$30-40$ & $104(42.27)$ \\
$40-50$ & $68(27.64)$ \\
$50-60$ & $29(11.78)$ \\
Gender & \\
Male & $134(54.47)$ \\
Female & $112(45.52)$ \\
Education & \\
Illiterate & $63(25.60)$ \\
Primary & $115(46.74)$ \\
Secondary & $43(17.47)$ \\
Higher secondary & $18(7.31)$ \\
Graduates & $7(2.84)$ \\
Occupation & $156(63.41)$ \\
Daily wage labor & $43(17.07)$ \\
Housewife & $38(15.44)$ \\
Salaried & $9(3.65)$ \\
Small-scale businessman & \\
\hline
\end{tabular}

Table 2: Knowledge about leprosy among slum study participants $(n=246)$

\begin{tabular}{|c|c|c|}
\hline \multirow[t]{2}{*}{ Knowledge variables } & \multicolumn{2}{|c|}{$\begin{array}{l}\text { Knowledge } \\
\text { Frequency (\%) }\end{array}$} \\
\hline & Present & Absent \\
\hline Are you aware about leprosy dis & $192(78.04)$ & $54(21.95)$ \\
\hline $\begin{array}{l}\text { Do you know national leprosy } \\
\text { eradication program }\end{array}$ & $46(18.66)$ & 200 \\
\hline Leprosy is bacterial disease & $(36.66)$ & $156(63.4$ \\
\hline $\begin{array}{l}\text { Do you know sign and symptoms of } \\
\text { leprosy }\end{array}$ & 6) & 1.46) \\
\hline Is it highly infective & $101(41.02)$ & $145(58.94)$ \\
\hline Is it l & 71( & 17 \\
\hline $\begin{array}{l}\text { Leprosy is transmitted by close } \\
\text { contact }\end{array}$ & $146(59.34)$ & $53(21.54)$ \\
\hline $\begin{array}{l}\text { Is it major public health problem in } \\
\text { India }\end{array}$ & $89(36.08)$ & $157(63.82)$ \\
\hline Is leprosy complete $(100 \%)$ curable & 140 & $106(43.08)$ \\
\hline Is it the dise & & 79 \\
\hline $\begin{array}{l}\text { Highly effective anti-leprosy treatment } \\
\text { available at Primary Health Centre/ } \\
\text { Community Health Centre }\end{array}$ & $130(52.92)$ & $116(47.15)$ \\
\hline $\begin{array}{l}\text { Anti-leprosy drugs are available free } \\
\text { of cost to everybody at Primary Health }\end{array}$ & $113(46.07)$ & $133(54.06)$ \\
\hline $\begin{array}{l}\text { Centre/Community Health Centre } \\
\text { Could health education raise } \\
\text { knowledge about leprosy }\end{array}$ & $127(51.63)$ & 37) \\
\hline
\end{tabular}

Table 3: Knowledge score category-wise distribution of respondents $(n=246)$

\begin{tabular}{ll}
\hline Knowledge category & Frequency (\%) \\
\hline Poor: $0-4$ & $137(55.69)$ \\
Fair: $5-8$ & $78(31.70)$ \\
Good: $9-13$ & $31(12.60)$ \\
\hline
\end{tabular}

The similarity in observations could be due to unauthorized slum habitations, migration problem, low literacy status, poverty, lack of public healthcare services, and traditional belief which adversely affect the behavior of community toward health and disease.

This study identified that $78 \%$ of slum dwellers responded about leprosy disease and $12.6 \%$ reported good knowledge about leprosy; 
Table 4: Association between sociodemographic characteristics and knowledge status about leprosy among study subjects ( $\mathrm{n}=246$ )

\begin{tabular}{|c|c|c|c|c|}
\hline \multirow[t]{2}{*}{ Demographic characteristic } & \multicolumn{4}{|c|}{ Frequency (\%) } \\
\hline & Poor & Fair & Good & $\chi^{2}, \mathrm{p}$ value \\
\hline \multicolumn{5}{|l|}{ Age (years) } \\
\hline $18-30$ & $23(9.34)$ & 15 (6.09) & $7(2.84)$ & 24.69 \\
\hline $30-40$ & $74(30.08)$ & $20(8.13)$ & $10(4.06)$ & $0.0004^{* *}$ \\
\hline $40-50$ & $33(13.41)$ & $26(10.56)$ & $9(3.65)$ & \\
\hline $50-60$ & $7(2.84)$ & 17 (6.91) & $5(2.03)$ & \\
\hline \multicolumn{5}{|l|}{ Gender } \\
\hline Male & $78(31.70)$ & 38 (15.44) & 18 (7.31) & 1.53 \\
\hline Female & 59 (23.98) & $40(16.26)$ & $13(5.28)$ & $0.46^{*}$ \\
\hline \multicolumn{5}{|l|}{ Education } \\
\hline Illiterate & $41(1.22)$ & $22(0.70)$ & $0(0.00)$ & 69.53 \\
\hline Primary & $80(1.57)$ & $29(2.28)$ & $6(1.57)$ & $0.0001^{* *}$ \\
\hline Secondary & $13(1.22)$ & $16(6.49)$ & $14(7.89)$ & \\
\hline Higher secondary & $3(0.35)$ & $8(5.08)$ & $7(46.49)$ & \\
\hline Gradates & $0(0.17)$ & $3(1.92)$ & $4(22.98)$ & \\
\hline \multicolumn{5}{|l|}{ Occupation } \\
\hline Daily wage labor & $96(39.02)$ & $54(21.95)$ & $6(2.43)$ & $\begin{array}{l}34.21 \\
0.0001^{* *}\end{array}$ \\
\hline Housewife & $23(9.34)$ & $9(3.65)$ & $11(4.47)$ & \\
\hline Salaried & $16(6.50)$ & $12(4.87)$ & $10(4.06)$ & \\
\hline Businessman & $2(0.81)$ & $3(1.21)$ & $4(1.62)$ & \\
\hline
\end{tabular}

${ }^{*} \mathrm{p}<0.05$ and ${ }^{* *} \mathrm{p}<0.001$

however, a study conducted by John AS from Kolkata [9] observed that majority of participants had some knowledge about leprosy. Around $58.3 \%$ were responded the sign and symptoms of leprosy; however, a study conducted in Secunderabad showed $27 \%$ aware about sign and symptoms of leprosy. In our study, $59.3 \%$ of study participants reported that leprosy has been transmitted by close contact. Similar findings have also been reported by Grewal I from urban slum area of Delhi [11]; however, a study conducted in Secunderabad [10] reported shocking exact opposite situation (72\%) among study subjects. The study revealed that $56.7 \%$ and $52.9 \%$ of respondents believed that leprosy is curable disease and availability of highly effective antileprosy treatment at Primary Health Centre/Community Health Centre as public health institutions; however; $46 \%$ knew that treatment is of free of cost. Almost similar findings have also been reported by Danturty I from Secunderabad [10] study about antileprosy treatment, but poor knowledge was observed about complete curability of disease. A study conducted by Grewal I from Delhi [11] observed that 70\% of participants knew that leprosy is $100 \%$ curable disease. As leprosy services are integrated into general healthcare services by the Government of India which resulted in increased awareness of community toward leprosy disease. Similarly, extensive campaign against leprosy by nongovernmental and voluntary organizations played a crucial role about leprosy among slum dwellers.

The study highlights that $36.6 \%$ of participants were responded about the cause of leprosy. Apparently, similar findings 30.7\% and 33.3\% have also been reported by a study conducted by Kolkata [9] and Delhi slum [11]. It was shocking that $18.6 \%$ knew about the National Leprosy Eradication Programme launched by the Government of India to tackle leprosy at national level; however, $46 \%$ responded regarding the availability of free of cost antileprosy treatment at government peripheral institutions. A study conducted by Grewal I from Delhi [11] reported that more than half of participants were not aware of free of cost of antileprosy treatment could be due to poor implementation of leprosy services or less importance to disease as the elimination of leprosy is achieved at local, state, and national level.

The present study revealed that age, education, and occupational status of slum community members have been significantly associated with knowledge about leprosy. A study conducted by John AS from Kolkata [9] reported that age and educational status were significantly associated with leprosy knowledge. A study conducted in Utter Pradesh, India [12], also recorded that age is significantly associated with knowledge about leprosy. As age increases, knowledge also increases reported by both the studies and results are comparable with the present study. The study described poor knowledge of study participants toward leprosy could be due to illiteracy, poverty, negative attitude toward modern healthcare services, ignorance, and slum habitations. Similarly, lack of local administrative authority, poor sensitization of community about health, and diseases by health organizations as well as the negative attitude of healthcare personnel could also contribute to poor performance by respondents. To overcome the existing poor knowledge of slum community [55.6\%] towards leprosy; needs training and retraining of peripheral health care workers, motivation and inculcate positive attitude by District Leprosy Control Unit. National Leprosy Eradication Programme services should be reached at grass root level by incorporating the model of public - private partnership as well as involvement of Non Governmental Organizations to improve the knowledge of community towards leprosy as reported by Mohite [13] from Satara district, Maharashtra.

\section{CONCLUSION}

The study concluded that urban slum community has had a poor knowledge about leprosy could be responsible for reporting of new cases of leprosy. Although leprosy elimination achieved at district level, need continues support from the government as well as nongovernmental agencies to achieve zero prevalence rate of leprosy, so there would not be a chance of reemerging of disease.

\section{ACKNOWLEDGMENT}

The author acknowledges to Dr. Durgawale PM, Prof and Head Department of Community Medicine, KIMSU, Karad, for support, guidance, and motivation for the research study. The study participants, medical social workers, and supporting staff from the Department of Community Medicine for their participation and support.

\section{AUTHORS CONTRIBUTIONS}

Mohite RV engaged in study design, data collection, analysis and preparation of manuscript as well as publication.

\section{CONFLICTS OF INTERESTS}

None decleaded. 


\section{REFERENCES}

1. Dharmshakyu NS. Overview of leprosy problem in India and strategies of national leprosy eradication programme. Indian J Lepr 1990;62:34-9.

2. Singh S, Sinha AK, Banerjee BG, Jaiswal N. Knowledge, beliefs and perception of leprosy. Disabil CBR Inclusive Dev 2012;23:67-75.

3. Jena S, Jena M, Patro M, Mishra S, Panda M, Dash M. Patterns of prescription and ADR monitoring of drugs in the management of neuropathic pain in a tertiary care teaching hospital. Int J Pharm Pharm Sci 2014;6:246-51.

4. Mohite RV. Evaluation of national leprosy eradication programme in Satara district, Maharashtra. Indian J Lepr 2011;83:139-43.

5. Mohite RV, Mohite VR. Differential trend of leprosy in rural and urban area of Western Maharashtra. Indian J Lepr 2013;85:11-8.

6. Mohite RV, Mohite VR. Patient satisfaction in national leprosy eradication programme. Bangladesh J Med Sci 2013;12:305-9.

7. Lakshmi R, Liniya S, Vijayalakshmi S. Dapsone induced hypersensitivity
syndrome-A case report. Int J Pharm Pharm Sci 2015;7:585-7.

8. Singal A, Sonthalia S. Leprosy in post-elimination era in India: Difficult journey ahead. Indian J Dermatol 2013;58:443-6.

9. John AS, Rao PS. Awareness and attitude towards leprosy in an urban slum of Kolkata, India. Indian J Lepr 2009;81:135-40.

10. Grewal I, Negi Y, Kishore J, Adhish S. Knowledge and attitude about leprosy in Delhi in post elimination phase. Indian J Lepr 2013;85:123-7.

11. Danturty I, Manchala S, Jairaj S. Community based study of knowledge, attitude and practices towards leprosy in an urban slum in Secunderabad, Telangana. J Med Sci Clin Res 2016;4:13527-31.

12. Barkataki P, Kumar S, Rao PS. Knowledge of and attitudes to leprosy among patients and community members: A comparative study in uttar pradesh, India. Lepr Rev 2006;77:62-8.

13. Mohite RV, Mohite VR. Knowledge and work performance of multipurpose workers under national leprosy eradication programme in Satara district, Maharashtra. Indian J Lepr 2012;84:137-44 